\title{
Radioiodine treatment: an historical and future perspective
}

\author{
Patricia Borges de Souza1 and Christopher John McCabe² \\ 'Department of Medical Sciences, Section of Endocrinology and Internal Medicine, University of Ferrara, Ferrara, Emilia-Romagna, Italy \\ 2Institute of Metabolism and Systems Research, Birmingham Health Partners, University of Birmingham, Birmingham, UK
}

Correspondence should be addressed to C J McCabe: C.J.MCCABE.MED@bham.ac.uk

This paper is part of a thematic review section celebrating 80 Years of the Use of Radioiodine. The guest editor for this section was Christopher John McCabe. Christopher John McCabe was not involved in the review or editorial process for this paper, on which he is listed as an author.

\section{Introduction}

Radioiodine (RAI) therapy has been used to treat thyroid diseases for around 80 years, and yet it is only relatively recently that we are beginning to manipulate its use, as we understand more of the cellular complexities which govern its success. From the benign nature of hyperthyroidism to malignant thyroid carcinomas and their metastases, RAI has profoundly changed the management of thyroid disorders. However, the complex journey which has elicited this simple therapy is worth exploring.

Standing on the shoulders of giants, it is first critical to acknowledge the work of Dr E Bauman who in 1895 spilled concentrated nitric acid on a sample of the thyroid gland and observed purple fumes rising from it, concluding that the thyroid contained iodide. Prior to that in the early 1800s, Joseph Gay-Lussac had based the element's name on the Greek word iodes, literally 'violet-like'. In 1916 an American biologist, David Marine, of Ohio, showed that goitre was caused by a lack of iodide in the diet. And of course, the ultimate discovery of therapeutic RAI owes an additional debt to the Nobel Prize-winning research of Pierre and Marie Joliot-Curie, for their description and isolation of artificial radioactive elements.

\section{Early meetings and collaborations}

A direct catalyst in the journey towards therapy occurred on November 12, 1936, at a Harvard Medical School luncheon seminar entitled 'What Physics Can Do for Biology and Medicine'. Dr Karl Compton, president of the Massachusetts Institute of Technology (MIT), mentioned that the Nobel prize-winning physicist Enrico Fermi had successfully produced by neutron bombardment several short half-life radioactive isotopes in his laboratory (Fermi 1934). Listening to Compton's lecture was a select group of clinicians and scientists interested in iodine metabolism. They included Saul Hertz, then Director of The Massachusetts General Hospital (MGH)'s Thyroid Unit, Earl Chapman, a private doctor who worked parttime at MGH, and Howard Means, then head of the Department of Medicine at MGH. Hertz reportedly asked Compton, 'Could iodine be made radioactive artificially?', while at the end of the lecture, Dr Means asked Compton about the actual availability of RAI. A few days later, after discussing the question with his collaborator Dr Robley Evans, Compton replied to Dr Hertz by letter and a fruitful MGH-MIT collaboration was born.

Several meetings and interactions between Means, Hertz and Evans subsequently took place to discuss the potential utility of Fermi's radioactive isotopes, which would include the use of rabbits for the study of thyroid metabolism. Preliminary experiments confirmed they could indeed produce ${ }^{128} \mathrm{I}$ at MIT by irradiating ethyl iodide with a radon-beryllium neutron source. However, the isotope obtained had a 25-min half-life and could therefore only be used for short-term experiments. Given the positive assessment of ${ }^{128}$ I production and the general interest in the project, an initial $\$ 3000$ of funding allowed the project to begin in earnest (Ehrhardt \& Gulec 2020, Fahey \& Grant 2021).

Dr Arthur Roberts, a skilful physicist, joined the team in September 1937. Roberts started producing ${ }^{128}$ I, at first using beryllium and radon recovered from local 
hospitals. Later, the team built a home-made neutron source that would contain beryllium and reprocessed radium, recovered from radium plaques and needles: ethyl iodide would be irradiated for 1 or $2 \mathrm{~h}$ by immersing it in the neutron source (Hertz et al. 1938) and concentrated to obtain radioactive silver iodide $\left(\mathrm{Ag}^{128} \mathrm{I}\right)$ precipitate. The method could be performed quickly and would allow them to isolate up to $1 \mathrm{mg}^{128}$ I (Roberts \& Irvine 1938).

\section{Initial animal experiments}

The MGH-MIT group began experimenting on rabbits for the following 8 months, resulting in the first of a series of published manuscripts in May 1938 by Hertz et al.: 'Radioactive iodine as an indicator in the study of thyroid physiology' (Hertz et al. 1938). It may be worth noting that in the 1930s there were no committees regimenting animal experimentation, and the only ethical standard was the researchers' personal moral code. In total, 48 rabbits were injected with Ag128I precipitate. All animals survived. RAI uptake (RAIU) was assessed under different states of thyroid function: normal, hyperplastic, pregnancy and spontaneous goitre. The animals were then euthanised and tissue radioactivity measured using a GeigerMüller system calibrated to register beta radiations (Roberts \& Irvine 1938). Several tissues and body fluids were analysed; however, none compared positively to the RAIU of the thyroid gland. Results indicated that thyroidal RAI uptake was rapid and was dependent on the degree of hyperplasia. Moreover, the authors reported that small amounts of RAI could induce greater uptake by the thyroid than large doses, and, interestingly, previous administration of unlabelled iodine would decrease subsequent uptake. The landmark results obtained by Hertz and Roberts set the groundwork for all prospective therapeutic use of RAI (Ehrhardt \& Gulec 2020, Fahey \& Grant 2021). However, they appreciated the drawbacks of their discoveries. They only had around 30 min available from the moment of injection to the actual measurement, and animals had to be euthanised and the tissues minced so that low-penetrating beta radiation could be measured by direct contact with Geiger-Müller counters. A stronger neutron source and isotopes with longer half-lives were essential to eventually translate RAI into the clinical practice.

\section{Transformative funding opens the way to clinical trials}

After publicising and discussing their findings, MGH's Dr James Means was able to obtain \$30,000 from the

(c) 2021 Society for Endocrinology Published by Bioscientifica Ltd. Printed in Great Britain
Mary and Markle Foundation in New York to build the first cyclotron dedicated exclusively to biomedical research at MIT, which was fully operational by November 1, 1940. Until its completion, isotopes were supplied by the Berkley and Rochester cyclotrons and included ${ }^{130} \mathrm{I},{ }^{131} \mathrm{I}$ and ${ }^{126} \mathrm{I}$, having half-lives of 12.5 h, 8 days and 13 days, respectively.

Interestingly, Joe Hamilton and Mayo Soley from the Berkeley cyclotron laboratories had begun experimenting with the biodistribution of 128I and other radioactive elements (Hamilton 1938). When their cyclotron produced the isotopes ${ }^{130} \mathrm{I}$ and ${ }^{131} \mathrm{I}$, they became interested in iodine metabolism, probably inspired by the previous results obtained via the MGH-MIT studies. They analysed the rates of iodine excretion in normal individuals and patients suffering from different thyroid disorders, as well as determining thyroidal radioiodine uptake in those patients who underwent thyroidectomy. By June 1939, they confirmed RAIU by the human thyroid in the same fashion observed in Hertz's rabbits and suggested that it was possible to obtain a dynamic picture of iodine metabolism by assessing the rates of uptake and discharge by the thyroid. They also reported a lack of RAIU by one cancerous thyroid, which potentially represents the first reported patient with reduced tumoural uptake of RAI. It was this initial assessment of RAIU in humans that led to the very first treated patient with oral ${ }^{130}$ I by Hertz about a year and a half later, in early 1941. In fact, the MGH-MIT group continued to extend their research on animals (Hertz et al. 1940, Hertz \& Roberts 1941) and began human experimentation (Hertz \& Roberts 1942a, Hertz et al. 1942) between August 1939 and July 1941.

Dubbed the 'radioactive cocktail', it was actually around $90 \%{ }^{130} \mathrm{I}$, as well as a small amount of ${ }^{131} \mathrm{I}$, a product of MIT's cyclotron, obtained by deuteron bombardment of tellurium. By that time, the MGH-MIT group had developed a relatively accurate calibration of the GeigerMüller counter to measure gamma radiation. The first assessment of their trials led to a better understanding of iodine metabolism in Graves' disease and was presented at the meeting of the American Society for Clinical Investigation in Atlantic City in May 1942 (Hertz \& Roberts $1942 b$ ). Interestingly, Hamilton was at that same meeting to report his experience in treating three hyperthyroidism patients with 130I during October 1941 (Hamilton 1942). Over the next two years, a series of 29 patients diagnosed with hyperthyroidism were enlisted and treated by Hertz with ${ }^{130}$ I. However, results were not reported until several years later, in 1946, as Hertz joined the navy in 1943 to fight in World War II. 
During those years, joint research continued via Drs Evans and Chapman, in which 22 patients were treated for hyperthyroidism with only RAI, whereas Hertz' patients had been treated with both RAI and unlabelled iodine, alone or combined. Chapman was not convinced about the efficiency of Hertz's treatment protocol, whereas Hertz disagreed with the excessively high doses of RAI that Chapman administered.

Evans and Chapman submitted a paper for publication without Hertz's name. The editor asked Hertz for his findings on the initial series. The Journal of the American Medical Association then published competing papers from both authors in May 1946 (Chapman \& Evans 1946, Hertz $\&$ Roberts 1946), announcing a new therapeutic tool for hyperthyroidism and opening the doors to a new era in thyroid pathological outcome (Ehrhardt \& Gulec 2020, Fahey \& Grant 2021). Very quickly, RAI was introduced into clinical practice and several groups began to report their experience in the treatment of not only hyperthyroidism but also thyroid cancer.

In 1949, Dr Hertz established the first Nuclear Medicine Department at the Massachusetts's Women's Hospital, expanding his research into other areas of cancer utility using radionuclides (Hertz 2019). However, Hertz, perhaps the pivotal figure in the adoption of radioiodine treatment for thyroid cancer and hyperplasia, died soon after in 1950, the result of sudden heart attack.

Albert Keston et al. reported RAIU in a thyroid cancer metastasis in 1942 (Keston et al. 1942) and this finding was crucial in understanding the potential role of thyroid ablation with RAI as therapy. However, the first clinical use of RAI for the diagnosis and treatment of differentiated thyroid cancer belongs to Dr Samuel Seidlin (Seidlin et al. 1946, 1949), who had also reported that RAIU could be induced by injection of thyrotrophic hormone, demonstrating RAIU in 8 of 14 cases of metastatic thyroid carcinoma (Seidlin et al. 1948). In 1951, 131I was the first radiopharmaceutical to receive approval from the Food and Drug Administration, to be used for the treatment of thyroid disease, thus initiating the clinical history of radioiodine. Subsequently in 1963, a report published in Journal of the American Medical Association by Haynie and Beierwaltes described a 14-year follow-up of 200 patients with thyroid carcinoma treated with ${ }^{131}$ I between 1947 and 1960, in which 67\% cases with regional lymph node metastases and 53\% with distant metastases were apparently free of disease (Haynie et al. 1963). Results were remarkable and laid the groundwork for treating thyroid cancer with radioiodine.

\section{What now for radioiodine treatment?}

So, approximately 80 years later, where does the future lie? Radioiodine treatment, whilst a unique therapeutic gem, clearly has flaws and imperfections and does not serve all patients equally. In metastatic thyroid cancer specifically, failure is accompanied by grim outcome statistics. In ever more detail we now understand at the epigenetic, transcriptional, post-transcriptional, translational and post-translational levels how dysregulation of the sodium iodide symporter contributes to treatment failure. Acting on these data a myriad of approaches are beginning to address this, and will doubtless continue to be improved upon. Combinations of drugs that induce NIS expression more broadly than in the subsets of patients currently benefitting from BRAF and MEK inhibition have the potential to be transformative. Clearly, we also need to be better able to increase NIS subcellular localisation to the plasma membrane, following induction of its expression, and via approaches that target NIS intracellular processing (Fletcher et al. 2020). Precision and tailored dosing at the individual level may obviate side effects and bring radioiodine treatment in line with the patient-specific dosing of other cancer therapies. Ultimately, we may even need to come full circle and ask again 'What Physics Can Do for Biology and Medicine'. In addition to figuring out the biology, new radionuclides which are effectively transported via NIS may ultimately elicit improved imaging, leading to enhanced targeted ablation strategies, particularly of metastases. Combined radionuclide and cellular advances could thus sustain radioiodine treatment for a further 80 years, saving lives via the manipulation of this simple and effective therapy.

\section{Declaration of interest}

The authors declare that there is no conflict of interest that could be perceived as prejudicing the impartiality of this review.

\section{Funding}

This work was supported by the Medical Research Council, the University of Birmingham and the University of Ferrara.

\section{References}

Chapman EM \& Evans RD 1946 The treatment of hyperthyroidism with radioactive iodine. JAMA 131 86-91. (https://doi.org/10.1001/ jama.1946.02870190010003)

Ehrhardt Jr JD \& Gulec S 2020 A review of the history of radioactive iodine theranostics: the origin of nuclear ontology. Molecular Imaging (c) 2021 Society for Endocrinology Published by Bioscientifica Ltd. Printed in Great Britain 
and Radionuclide Therapy 29 88-97. (https://doi.org/10.4274/mirt. galenos.2020.83703)

Fahey FH \& Grant FD 2021 Celebrating eighty years of radionuclide therapy and the work of Saul Hertz. Journal of Applied Clinical Medical Physics 22 4-10. (https://doi.org/10.1002/acm2.13175)

Fermi E 1934 Radioactivity induced by neutron bombardment. Nature $\mathbf{1 3 3}$ 757-757. (https://doi.org/10.1038/133757a0)

Fletcher A, Read ML, Thornton CEM, Larner DP, Poole VL, Brookes K, Nieto HR, Alshahrani M, Thompson RJ, Lavery GG, et al. 2020 Targeting novel sodium iodide symporter interactors ADP-ribosylation factor 4 and valosin-containing protein enhances radioiodine uptake. Cancer Research 80 102-115. (https://doi.org/10.1158/0008-5472.CAN-19-1957)

Hamilton JG 1938 The rates of absorption of the radioactive isotopes of sodium, potassium, chlorine, bromine, and iodine in normal human subjects. American Journal of Physiology: Legacy Content 124 667-678. (https://doi.org/10.1152/ajplegacy.1938.124.3.667)

Hamilton JGL 1942 Proceedings of the thirty-fourth annual meeting of the American Society for Clinical Investigation held in Atlantic City, N. J., May 4, 1942. Journal of Clinical Investigation 21 619-649. (https:// doi.org/10.1172/JCI101340)

Haynie TP, Nofal MM, Beierwaltes WH 1963 Treatment of thyroid carcinoma with I131: results at fourteen years. JAMA 183 303-306. (https://doi.org/10.1001/jama.1963.03700050035008)

Hertz B 2019 A tribute to Dr. Saul Hertz: the discovery of the medical uses of radioiodine. World Journal of Nuclear Medicine 18 8-12. (https://doi. org/10.4103/wjnm.WJNM_107_18)

Hertz S \& Roberts A 1941 Radioactive iodine as an indicator in thyroid physiology III: iodine collection as a criterion of thyroid function in rabbits injected with thyrotropic hormone 1. Endocrinology 29 82-88. (https://doi.org/10.1210/endo-29-1-82)

Hertz S \& Roberts A $1942 a$ Radioactive iodine as an indicator in thyroid physiology. $\mathrm{V}$. The use of radioactive iodine in the differential diagnosis of two types of Graves' disease. Journal of Clinical Investigation 21 31-32. (https://doi.org/10.1172/JCI101276)

Hertz S \& Roberts A $1942 b$ Proceedings of the thirty-fourth annual meeting of the American Society for Clinical Investigation held in
Atlantic City, N. J., May 4, 1942. Journal of Clinical Investigation 21 619-649. (https://doi.org/10.1172/JCI104783)

Hertz S \& Roberts A 1946 Radioactive iodine in the study of thyroid physiology: VII. The use of radioactive iodine therapy in hyperthyroidism. JAMA 131 81-86. (https://doi.org/10.1001/ jama.1946.02870190005002)

Hertz S, Roberts A \& Evans RD 1938 Radioactive iodine as an indicator in the study of thyroid physiology. Experimental Biology and Medicine $\mathbf{3 8}$ 510-513. (https://doi.org/10.3181/00379727-38-9915P)

Hertz S, Roberts A, Means JH \& Evans RD 1940 Radioactive iodine as an indicator in thyroid physiology. American Journal of Physiology: Legacy Content 128 565-576. (https://doi.org/10.1152/ ajplegacy.1940.128.3.565)

Hertz S, Roberts A \& Salter WT 1942 Radioactive iodine as an indicator in thyroid physiology: IV. The metabolism of iodine in Graves' disease. Journal of Clinical Investigation 21 25-29. (https://doi.org/10.1172/ JCI101275)

Keston AS, Ball RP, Frantz VK \& Palmer WW 1942 Storage of radioactive iodine in a metastasis from thyroid carcinoma. Science 95 362-363. (https://doi.org/10.1126/science.95.2466.362)

Roberts A \& Irvine JW 1938 Concentration of radiohalides, and failure to observe gamma-rays from I128. Physical Review 53 609-609. (https:// doi.org/10.1103/PhysRev.53.609.2)

Seidlin SM, Marinelli LD \& Oshry E 1946 Radioactive iodine therapy: effect on functioning metastases of adenocarcinoma of the thyroid. JAMA 132 838-847. (https://doi.org/10.1001/ jama.1946.02870490016004)

Seidlin SM, Oshry E \& Yalow AA 1948 Spontaneous and experimentally induced uptake of radioactive iodine in metastases from thyroid carcinoma: a preliminary report. Journal of Clinical Endocrinology and Metabolism 8 423-432. (https://doi.org/10.1210/ jcem-8-6-423)

Seidlin SM, Rossman I, Oshry E \& Siegel E 1949 Radioiodine therapy of metastases from carcinoma of the thyroid: a six-year progress report. Journal of Clinical Endocrinology and Metabolism 9 1122-1137. (https:// doi.org/10.1210/jcem-9-11-1122)

Received in final form 3 March 2021

Accepted 10 March 2021

Accepted Manuscript published online 10 March 2021 (c) 2021 Society for Endocrinology Published by Bioscientifica Ltd. Printed in Great Britain 